\title{
A New Compact UWB Microstrip BPF for Wireless Communication Using DGS
}

\author{
Tasher Ali Sheikh and Janmoni Borah
}

\begin{abstract}
A novel compact ultra-wide band micro-strip band-pass filter has proposed in this paper for the application of wireless communication systems. By using DGS, desired UWB micro-strip BPF has designed. The designed filter has maintained lesser insertion loss, high selectivity and very good return loss. The proposed pass band filter has guaranteed the sharpness of skirts of the parameters because of appearances of transmission zero near the each pass band edges. The presences of three poles at the pass band in the designed UWB BPF could scale up the bandwidth and enhanced the selectivity. At $6 \mathrm{GHz}$ centre frequencies, the $3 d B$ fractional bandwidth is $56.07 \%$. The simulated values of the insertion loss and return loss of the proposed filter are $-0.0184 \mathrm{~dB}$ and $-43.84 d B$ respectively. The Ansoft high frequency structural simulator has used for frequency response of the designed filter.
\end{abstract}

\section{Keywords}

Bandpass filter (BPF);

Ultra wideband (UWB);

Defected ground structure (DGS);

Fractional Bandwidth (FBW);

Insertion loss;

Return loss;

Group delay.

\section{INTRODUCTION}

The ultra-wideband technology play vital role in the field of wireless communication systems after allowed unlicensed operation of RF band from $3.1 \mathrm{GHz}$ to $10.60 \mathrm{GHz}$ in the year 2002 [1]. It has numerous demands in wireless communication such as transmitting high data rate and consumes low power while transmitting. While designing the UWB filter there has met many challenges to attain the required UWB bandwidth. The UWB is filtering now-a-days becoming a hot topic of research in the field of microwave communication because of nonstop increases of number of users in wireless communication systems. Compact and higher performance filter are always obligation to encouraging emerging end users to enhance the sharpness of the skirts and multimedia services [2-7]. In recent times, DGS is extensively used for UWB filter design, because it gives higher system performance rather than other. In most of the communication systems, filter act as vital elements and higher quality filter enhance the systems performance. A BPF is the central component that has used as a transceiver in the communication systems, which is play as a significant character intended for choosing the desired band and attenuated the unwanted frequency in a precise bandwidth. Today designing such a wide passband filter that has a multiple services, that has a vital topic of research for the researcher, which is carried out in recent times. In recent years, there is wide and rapid development of Ultra-Wideband technology, especially in [8-9] in field of radio frequency systems. In microstip filter design, DGS has used widely in current time to realize the band pass responses like compactness with low insertion loss, exact coupling capability, and impedance ratio (R) and higher design of freedom for choosing the length ratio $(\mu)$ to meet the specific band [10-11]. The centre frequency and fraction BW can calculate by (1) and (2):

$$
\begin{aligned}
& \omega_{0}=\sqrt{\omega_{1} \omega_{2}} \\
& F B W=\frac{\omega_{1}-\omega_{2}}{\omega_{0}}
\end{aligned}
$$

Where in equation (1) and (2) $\omega_{1}$ and $\omega_{2}$ are lower and the upper cut-off frequencies respectively of the proposed filter.

\section{Design Procedure And Simulated RESULTS ANALYSIS}

The Schematic diagrams of the proposed Ultrawideband BPF is depicted in Fig.1, Fig.2 and Fig.3. The layout consists of one SIRs, a pair of I/O ports and a DGS structure that forms compactness and allows achieving the required pass-band for UWB wireless applications with a good return loss and 
insertion loss. The filter is designed on RT Duriod 5880 substrate with dielectric constant $\left(\epsilon_{r}\right)$ of 2.2, tangent loss $(\delta)$ of 0.0009 and a thickness of $0.787 \mathrm{~mm}$.

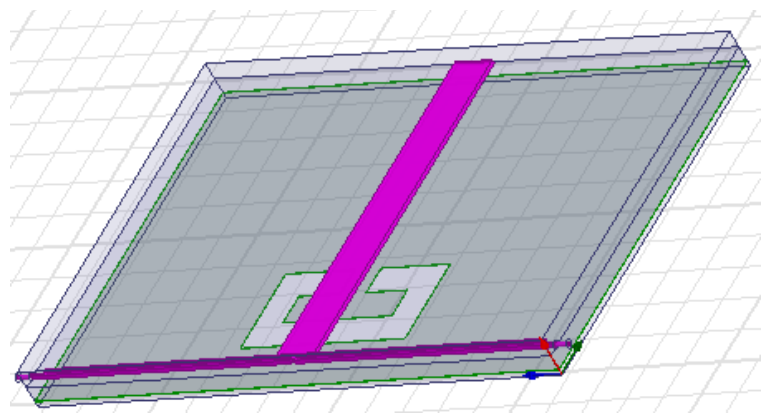

Fig 1. Structure of the Propose UWB BPF

The design specification of the UWB passband filter is based on the design response shown in Fig.4, and have a centre frequency $\left(f_{c}\right)$ is $6 \mathrm{GHz}$. The structures shown in Fig.2 and Fig. 3 are designed with a strip width of $0.2 \mathrm{~mm}$ and $3.85 \mathrm{~mm}$ to achieve high impedance $\left(\mathrm{Z}_{1}=78.17 \Omega\right)$ and low impedance $\left(\mathrm{Z}_{2}=47.33 \Omega\right)$ respectively. The fractional bandwidth (FBW) $56.07 \%$ so obtained is calculated by using Ansoft HFSS Simulator. The result shows a very low insertion loss $\left(\mathrm{S}_{21}\right)$ of $-0.0184 \mathrm{~dB}$ and return loss $\left(\mathrm{S}_{11}\right)$ of $-43.84 \mathrm{~dB}$ with centre frequency of $6 \mathrm{GHz}$. The design specific parameters considered in this paper are tabulated in Table.1.

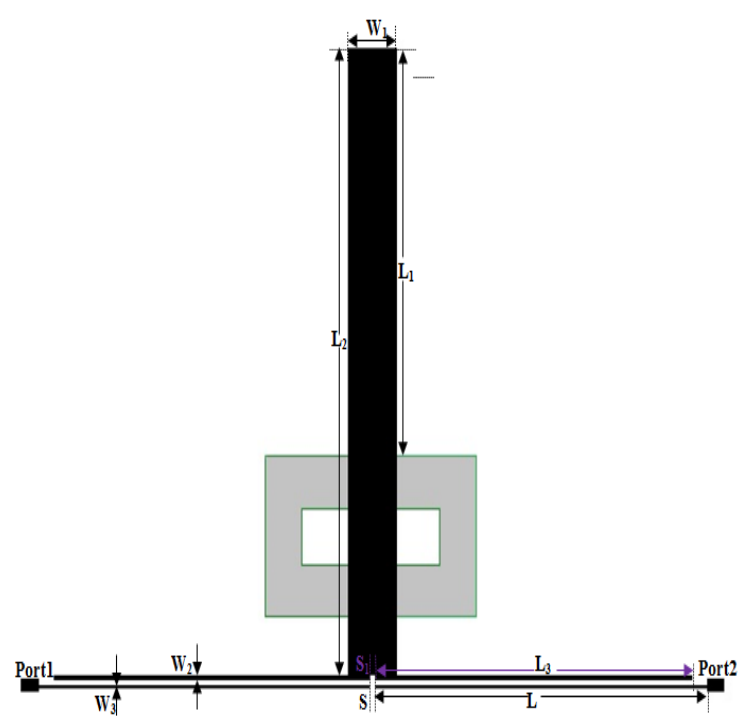

Fig 2. Propose UWB filter (front view).

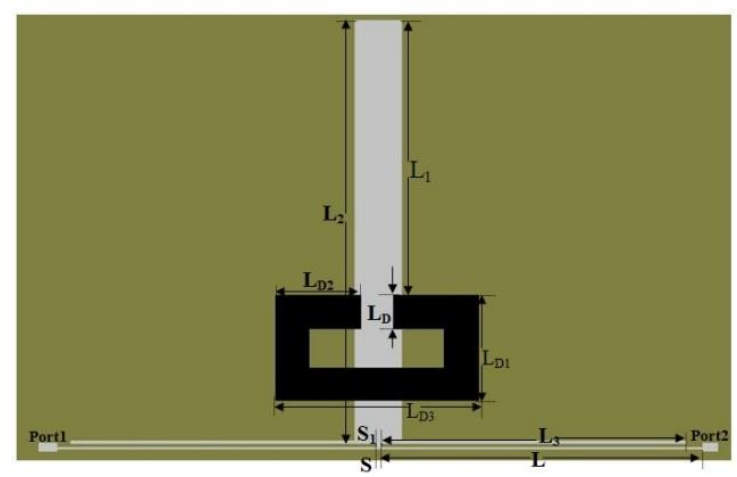

Fig 3.Propose UWB filter (back view).

From the obtained UWB responses, magnitude of $\mathrm{S}_{21}$ and the phase difference of transmission is shown in Fig.4. As seen from Fig.4, the two zeros $\mathrm{f}_{\mathrm{Z} 1}$ and $\mathrm{f}_{\mathrm{Z} 2}$ appears in each pass-band edges which granted the sharpness of the design filter scattering parameters and thus increases the selectivity.

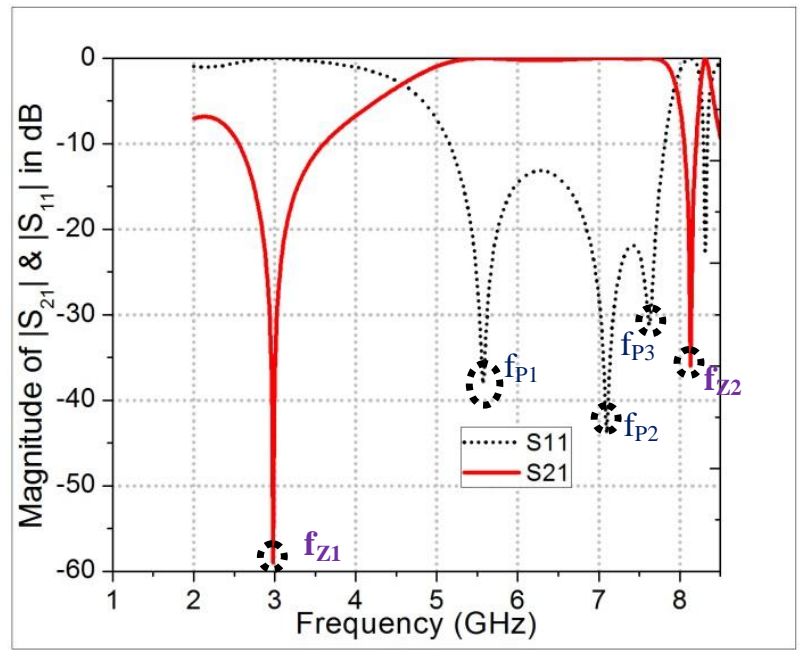

Fig 4. The Simulated $\left|S_{21}\right|$ and $\left|S_{11}\right|$ and their Phase difference.

The Fig. 4 also depicts the magnitude of $S_{11}$ and the phase difference of transmission of the UWB $\mathrm{BPF}$ responses. The three poles $\mathrm{f}_{\mathrm{P} 1}, \mathrm{f}_{\mathrm{P} 2}$ and $\mathrm{f}_{\mathrm{P} 3}$ that appear in pass-band enhance the bandwidth of the design filter. The results show a returns loss $\left(\mathrm{S}_{11}\right)$ of $-43.84 \mathrm{~dB}$ with centre frequency of $6 \mathrm{GH}$.The equations (3) and (4), shown below can be used for calculation of capacitance and the inductance of the DGS in [6].

$$
C=\frac{\omega_{c}}{Z_{0} g} \cdot \frac{1}{\omega_{0}^{2}-\omega_{c}^{2}}
$$

Tasher Ali Sheikh and Janmoni Borah "A Compact UWB Microstrip BPF for Wireless Communication Using DGS, International Journal of Advanced Engineering and Management, Vol. 2, No. 7, pp. 168-171, 2017. DOI: 


$$
L=\frac{1}{4 \pi^{2} f_{0}^{2} C}
$$

Where, $\mathrm{Z}_{0}$ is the Characteristic impedance of the input/output ports, $\omega_{c}$ is the cut-off frequency of the low-pass filter, and ' $\mathrm{g}$ ' used for lump element value of the prototype Low pass filter.

The Fig.5 show the group delays which varies between $0.12-0.13 \mathrm{~ns}$ at centre frequency of $6 \mathrm{GHz}$. The group delays are obtained by taking the derivative of the phase and are inversely proportional to bandwidth. The simulated results depict that the proposed UWB BPF filter presents a good and satisfactory delay.

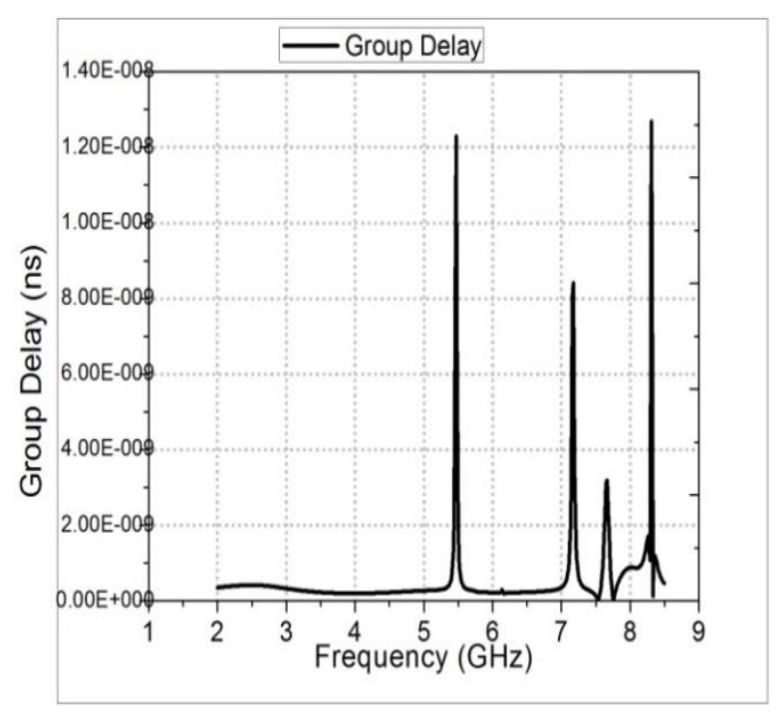

Fig 5.Simulated Group Delays for the filter.

The UWB band passfilter is realized using Rogers RT/ Duriod 5880 substratewith dielectric constant $\left(\epsilon_{r}\right)$ of 2.2. The substrate tangent loss $(\delta)$ is approximately 0.0009 and have a thickness of $0.787 \mathrm{~mm}$. It is design and tested by the HFSS Simulator. The Dimension \& design parameters details are listed in Table. 1 microstrip width consider here as $0.2 \mathrm{~mm}$. The dimension obtained for the BPF is minimum compare to the recently available filter. The size of it $19.1 \times 28 \mathrm{~mm}^{2}$ as can be depict from comparison Table.2.

Table1. Dimensions\& design parameters considered

\begin{tabular}{|c|c|c|c|}
\hline DGS value (mm) & Length $(\mathbf{m m})$ & Width $(\mathbf{m m})$ & Space $(\mathbf{m m})$ \\
\hline $\mathrm{LD}=1.5$ & $\mathrm{~L}=13.8$ & $\mathrm{~W} 1=2$ & $\mathrm{~S}=0.2$ \\
\hline $\mathrm{LD} 1=4.6$ & $\mathrm{~L} 1=11.9$ & $\mathrm{~W} 2=0.2$ & $\mathrm{~S} 1=0.2$ \\
\hline $\mathrm{LD} 2=3.7$ & $\mathrm{~L} 2=18.1$ & $\mathrm{~W} 3=0.15$ & \\
\hline $\mathrm{LD} 3=8.8$ & $\mathrm{~L} 3=13.25$ & & \\
\hline
\end{tabular}

Table 2.Comparison of proposed filter with some other exiting UWB BPF

\begin{tabular}{|c|c|c|c|c|c|}
\hline $\begin{array}{c}\text { Filter } \\
\text { Size } \\
\left(\mathbf{m m}^{\mathbf{2}}\right)\end{array}$ & $\begin{array}{c}\text { Passband } \\
(\mathbf{G H z})\end{array}$ & $\begin{array}{c}\left|\mathbf{S}_{\mathbf{1 1}}\right| \\
\mathbf{d B}\end{array}$ & $\begin{array}{c}\left|\mathbf{S}_{\mathbf{2 1}}\right| \\
\mathbf{d B}\end{array}$ & $\mathbf{F B W}$ & $\begin{array}{c}\text { Comparison of } \\
\text { model }\end{array}$ \\
\hline 284.2 & $4.6-10.6$ & 15 & 0.5 & 79 & Ref.[12] \\
\hline 840 & $3.1-10.6$ & 10.5 & 1.35 & 110 & Ref.[13] \\
\hline 204 & $3.1-10.6$ & 20 & 1 & 109 & Ref.[14] \\
\hline 450 & $3.1-10.6$ & 12.5 & 0.45 & 110 & Ref.[15] \\
\hline 108 & $3.1-10.6$ & 14 & 0.60 & 104 & Ref.[16] \\
\hline 120 & $3.1-10.6$ & 20 & 0.60 & 110 & Ref.[17] \\
\hline 534.8 & $4.57-7.95$ & 43.84 & 0.0184 & 56.07 & Proposed Design \\
\hline
\end{tabular}

\section{CONCLUSION}

A novel compact UWB BPF is obtained for the application of UWB wireless communication with centre frequency $\left(\mathbf{f}_{\mathbf{c}}\right)$ is $6 \mathrm{GHz}$, which was proposed here using microstrip SIRs and DGS. The proposed Filter has a major advantage of controlling mechanism of the resonating modes of the SIRs and thereby the pass band (PB) can be tuned. This control mechanism of the microstrip SIRs can be achieve by proper selection of the length ratio (u) along with the impedance ratio $(\mathrm{R})$ to match with the expected or desire responses for UWB band pass filter application. The circuit overall dimension is reduces in comparison with others conventional DGS UWB BPF. The filter which is proposed here, possess high return loss of $-43.84 \mathrm{~dB}$, low insertion loss $-0.0184 \mathrm{~dB}$ only and also better pass band selectivity in comparisons with available UWB BPF. The Fractional Bandwidths (FBW) of the filter is $56.07 \%$. The simulative results and analysis proves that proposed filter shows better performance compared to other cited works in this paper.

\section{REFERENCES}

[1] Maichalernnukul, K., Zheng, F., \& Kaiser, T. (2010, March). UWB MIMO cooperative relay systems: BER analysis and relay regions. In Information Sciences and Systems (CISS), 2010 44th Annual Conference on (pp. 1-6). IEEE.

[2] Sheikh, T. A., Borah, J., \& Roy, S. (2014). Bandwidth improvement in BPF using microstrip couple lines. ICSSP, 14, 105-109. DOI: $10.13140 / 2.1 .3254 .6881$

[3] Sheikh, T. A., Borah, J., Roy, S., \& Pandey, A. K. (2016). A New Compact Dual Band Microstrip BPF for GSM $(1.8 \mathrm{GHz})$ and WiMAX Using Asymmetric Stepped Impedance Resonators. In Proceedings of the International Conference on Recent Cognizance in Wireless Communication \&

Tasher Ali Sheikh and Janmoni Borah "A Compact UWB Microstrip BPF for Wireless Communication Using DGS, International Journal of Advanced Engineering and Management, Vol. 2, No. 7, pp. 168-171, 2017. DOI: 
Image Processing (pp. 581-587). Springer India.DOI: $10.1007 / 978-81-322-2638-3$ 65.

[4] Sheikh, T. A., Borah, J., \& Roy, S. (2015). Miniaturized Tri-Band BPF using Asymmetric SIRs and DGS. International Journal of Signal processing, Image processing and pattern recognition (IJSIP), 8(2), 337-346. DOI: $10.14257 /$ ijsip.2015.8.2.32.

[5] Sheikh, T. A., Borah, J., \& Roy, S. (2016). Design of compact bandpass filter for WiMAX and UWB application using asymmetric SIRs and DGS. Radioelectronics and Communications Systems, 59(6), 269273. DOI: $10.3103 / \mathrm{S} 0735272716060066$.

[6] Hong, J.-S. and Lancaster, M. J. (2001) Case Study for Mobile Communications Applications, in Microstrip Filters for RF/Microwave Applications, John Wiley \& Sons, Inc., New York, USA. doi: 10.1002/0471221619.ch12

[7] Chen, W. Y., Weng, M. H., Chang, S. J., Kuan, H., \& Su, Y. H. (2012). A new tri-band bandpass filter for GSM, WiMAX and ultrawideband responses by using asymmetric stepped impedance resonators. Progress In Electromagnetics Research, 124, 365-381. DOI: $\underline{\text { 10.2528/PIER11122010 }}$

[8] Kuo, T. N., Wang, C. H., \& Chen, C. H. (2007). A compact ultra-wideband bandpass filter based on split-mode resonator. IEEE Microwave and Wireless Components Letters, 17(12), 852-854.DOI: 10.1109/LMWC.2007.910483

[9] Shaman, H., \& Hong, J. S. (2007). A novel ultra-wideband (UWB) bandpass filter (BPF) with pairs of transmission zeroes. IEEE Microwave and Wireless Components Letters, 17(2), 121-123. DOI: 10.1109/LMWC.2006.890335

[10] Xu, J., Niu, Y., Cui, L., Miao, C., \& Wu, W. (2012). Analytical design of a microstrip UWB BPF with sharp rejection. Journal of Electronics (China), 29(5), 451-455. DOI: 10.1007/s11767-012-0830-y

[11] Pirani, S., Nourinia, J., \& Ghobadi, C. (2010). Band-notched UWB BPF design using parasitic coupled line. IEEE Microwave and Wireless Components Letters, 20(8), 444446..DOI: 10.1109/LMWC.2010.2049830.

[12] Lin, T., Long, J., \& Guo-qing, Y. (2011, October). A compact ultra-wideband (UWB) bandpass filter using microstrip T-shaped stub. In Computational Problem-Solving (ICCP), 2011 International Conference on (pp. 382-384). IEEE. DOI: 10.1109/ICCPS.2011.6092235

[13] Feng, W. J., \& Che, W. Q. (2011). Ultrawideband bandpass filter using broadband planar Marchand balun. Electronics
Letters, 47(3), 198-199. DOI: 10.1049/el.2010.7282

[14] Abbosh, A. M. (2012). Design method for ultra-wideband bandpass filter with wide stopband using parallel-coupled microstrip lines. IEEE Transactions on Microwave Theory and Techniques, 60(1), 31-38. DOI: 10.1109/TMTT.2011.2175241

[15] Feng, W. J., Che, W. Q., \& Eibert, T. F. (2011). Ultra-wideband bandpass filter based on transversal signal-interaction concepts. Electronics letters, 47(24), 1330 1331. DOI:10.1049/el.2011.2658.

[16] Duong, T. H., \& Kim, I. S. (2010). Steeply sloped UWB bandpass filter based on stubloaded resonator. IEEE microwave and wireless components letters, 20(8), 441-443. DOI: 10.1109/LMWC.2010.2049480

[17] Wu, H. W., Chen, Y. W., \& Chen, Y. F. (2012). New ultra-wideband (UWB) bandpass filter using triangle-ring multi-mode stubloaded resonator. Microelectronics Journal, 43(11), 857-862. DOI: $\underline{10.1016 / \text { j.mejo.2012.06.005. }}$

Tasher Ali Sheikh tasher372@gmail.com

North Eastern Regional Institute Of Science And Technology, India

Janmoni Borah borah1989@gmail.com North Eastern Regional Institute of Science And Technology, India

Tasher Ali Sheikh and Janmoni Borah "A Compact UWB Microstrip BPF for Wireless Communication Using DGS, International Journal of Advanced Engineering and Management, Vol. 2, No. 7, pp. 168-171, 2017. DOI: 